\title{
Taxonomic review of the genus Tambinia Stål (Hemiptera, Fulgoromorpha,Tropiduchidae) with descriptions of four new species from the Pacific region
}

\author{
Rong-rong Wang ${ }^{\dagger}$, Ai-Ping Liang ${ }^{\ddagger}$
}

Key Laboratory of Zoological Systematics and Evolution, Institute of Zoology, Chinese Academy of Sciences, 1 Beichen West Road, Chaoyang District, Beijing 100101, China

† urn:lsid:zoobank.org:author:02FAFFA8-66AA-47D3-AD21-1C9FDF58495A

¥ urn:lsid:zoobank.org:author:862BAA85-A5A9-44DE-A6E4-99D30C39B2C9

Corresponding author: Ai-Ping Liang (liangap@ioz.ac.cn)

Academic editor: Mike Wilson | Received 18 May 2011 | Accepted 18 August 2011 | Published 3 October 2011

urn:lsid:zoobank.org:pub:252D5F9C-86D3-42EA-834E-E4B516C7DD9D

Citation: Wang R, Liang A (2011) Taxonomic review of the genus Tambinia Stål (Hemiptera, Fulgoromorpha, Tropiduchidae) with descriptions of four new species from the Pacific region. ZooKeys 132: 13-31. doi: 10.3897/ zookeys.132.1571

\begin{abstract}
Four new species of Tambinia Stål (Hemiptera: Fulgoromorpha: Tropiduchidae), T. conus sp. n. (Papua New Guinea), T. macula sp. n. (Malaysia: Borneo), T. robustocarina sp. n. (Malaysia: Sabah) and T. sexmaculata sp. n. (Australia: Kuranda) are described and illustrated from the Pacific region. The diagnostic characters of this genus are redefined. A checklist and a key to the known species of Tambinia are provided.
\end{abstract}

\section{Keywords}

Tambinia, Tropiduchidae, Fulgoromorpha, new species, Pacific region

\section{Introduction}

The tropiduchid planthopper genus Tambinia was established by Stål (1859) for T. languida Stål, T. debilis Stål and T. rufoornata Stål, all from Sri Lanka. The type species, T. languida Stål, was fixed later by Distant (1906) by subsequent designation. Tam-

Copyright Rong-rong Wang,Ai-Ping Liang. This is an open access article distributed under the terms of the Creative Commons Attribution License, which permits unrestricted use, distribution, and reproduction in any medium, provided the original author and source are credited. 
binia is currently placed in the tribe Tambiniini Kirkaldy, 1907 (Metcalf 1954; Fennah 1982). The tropiduchid tribe Tambiniini, as redefined by Fennah (1982), comprises ten genera, Tambinia, Ossoides, Sumbana, Kallitaxila, Kallitambinia, Nesotaxila, Garumna, Paragarumna, Athestia and Biruga. However, in a recent study about tribe Tambiniini, Wang et al. (2009) established one new genus Garumnella, and Paragarumna was placed as a junior synonym of Garumna. O'Brien (2010) also established one new genus Diambon in the study of New World Tambiniini from palms. Members of Tambiniini are mainly distributed in the tropical regions of the World.

Although maximum attention has been paid to the monophyly and phylogeny in Fulgoromorpha, relatively little is known about the monophyly of both the Tambiniini and Tambinia and their relationships with other tropiduchid taxa in a cladistic sense. Only few papers provided valuable information about Tambinia: Wilson (1986) has stated that the Oriental and Australasian genera Nesotaxila and Kallitaxila appear to be most closely related to Tambinia. Asche and Wilson (1989) have indicated that some similarity exists in the aedeagal structure in Tambinia species and Ommatissus Fieber, 1875 (Trypetimorphini). A cladistic analysis is needed, but is beyond the scope of this paper.

While sorting and identifying Tropiduchidae from material on loan from the California Academy of Sciences, San Francisco, California, USA (CAS), National Museum of Natural History, Smithsonian Institution, Washington, DC, USA (USNM) and elsewhere, we found four new species of Tambinia from Papua New Guinea, Malaysia (Borneo, Sabah) and Australia (Kuranda). A revised generic diagnosis and a checklist of all known species of Tambinia are provided. A key to known species is also updated.

\section{Materials and methods}

Dry pinned specimens were used for the descriptions and illustrations. External morphology was observed under a stereoscopic microscope and characters were measured with an ocular micrometer. Abdomens were removed and macerated in cold 10\% $\mathrm{KOH}$ overnight. Precise dissections and cleaning of genitalic structures were finished in distilled water. Observations and drawings were done in glycerine under a compound light microscope. Photographs of the types were taken with a Nikon Coolpix 5400 digital camera. The digital images were then imported into Adobe Photoshop 8.0 for labeling and plate composition. Line figures were drawn with the aid of a camera lucida mounted on a Zeiss Stemi SV-11 stereomicroscope.

Specimens of three previously described species of the genus Tambinia, i.e. T. bizonata Matsumura, 1914, T. rubrolineata Liang, 2003 and T. similis Liang, 2003, have been examined. No specimens of the other seventeen previously described species were available for examination. However, there is no doubt concerning the identity of those species because the descriptions and illustrations were very clear and detailed. For detailed descriptions and figures of the seventeen previously described species, see Distant (1906, 1916), Fennah (1956, 1970, 1982), Ghauri (1976), Matsumura (1914), Meli- 
char (1914), Metcalf (1946, 1954), Men et al. (2009), Muir (1931), Wilson (1986) and Wilson and Malenovský (2007).

Specimens examined during the course of this study are deposited in the CAS, USNM and Bernice P. Bishop Museum, Honolulu, Hawaii, USA (BPBM). The terminology follows Bourgoin and Huang (1990) and Wang et al. (2009).

\section{Taxonomy}

\section{Genus Tambinia Stål, 1859}

http://species-id.net/wiki/Tambinia

Tambinia Stål, 1859: 316; Distant 1906: 276; Bierman 1910: 26; Muir 1931: 303; Metcalf 1954: 100; Liang and Jiang 2003. Type species Tambinia languida Stål by subsequent designation.

Ossa de Motschulsky 1863: 106; Bierman 1910: 26.

Diagnostic characters. Small-sized tropiduchids. Head (Figs 1A-E) with eyes narrowed than pronotum, distinctly produced in front of eyes and apically rounded, usually strongly dorsoventrally depressed and distinctly flattened in lateral view. Vertex (Figs 1A-E, 2-5A) tricarinate, disc of vertex (excluding median carina) depressed, posterior margin straight. Frons (Figs 2-5C) distinctly reclined caudad, somewhat flat and smooth, with or without median carina, rarely covered with sparsely microsetae. Clypeus triangular, relatively convex, with or without median carina, lateral margins not carinate. Rostrum short, not reaching mesotrochanters. Ocelli very small. Antennae with scape very small, pedicel cylindrical, covered with long setulae, sensory plaques present on top surface of pedical. Pronotum (Figs 2-5A) tricarinate, anterior margin straight and hind margin angulately excavate, with a single carina between eye and tegula. Mesonotum tricarinate. Hind titiae each with 2 distinct lateral spines; spinal formula of hind leg (4-5)-(4-5)-2; metatarsal segment II short and small. Forewings (Figs 1A-E) with oblique nodal line, apical portion flexing ventrad at this line, basal portion somewhat sub-hyaline, with or without granulate, thicker than apical portion, costal cell without cross veins.

Male genitalia. Pygofer (Figs 2F-H, 3E, 3G, 3H, 4E-G, 5F-H) symmetrical, dorsal margin deeply excavated to accommodate anal tube. Gonostylus (Figs $2 \mathrm{~F}, 2 \mathrm{H}, 3 \mathrm{E}$, $3 \mathrm{G}, 3 \mathrm{H}, 4 \mathrm{E}, 4 \mathrm{G}, 5 \mathrm{~F}, 5 \mathrm{H}$ ) elongate, bilaterally symmetrical, membranously fused with pygofer at base, with a conical, median process in ventral view, with a dorsally directed process arising from inner side near base and a laminate, inward directed, triangular process arising from inner side near middle. Periandrium (Figs 2F, 3E, 4E, 5F) dorsally connected with ventrobasal margin of anal tube, membranously fused with pygofer at ventral side, tube-like, distinctly sclerotized, surrounding aedeagus subapically or mesially, and visible in lateral view. Aedeagus (Figs 2F, 3E, 4E, 4F, 5F, 5G), asym- 
metrical, elongate and tubular, shaft of aedeagus (Figs 2F, 3E, 4E, 4F, 5F, 5G) slender and elongate, tubular, and sinuate in lateral view, subapically or mesially embraced in periandrium, endosoma membranous, with or without spines.

Discussion. The genus Tambinia comprises twenty-four species and is distributed in Oriental, Australasian and Afrotropical regions (Distant 1906, 1916, Fennah 1956, 1970, 1982, Ghauri 1976, Matsumura 1914, Melichar 1914, Metcalf 1946, 1954, Muir 1931, Wilson 1986, Wilson and Malenovský 2007). The tropiduchid planthoppers are usually weak fliers and have poor ability for long-distance migration by themselves. So, we indicate that new species have formed through geographical isolation over the disjunct distribution of the genus across widely separated island groups.

In external appearance, the genus Tambinia is similar to the Oriental and Australasian genera Nesotaxila, Kallitaxila and Kallitambinia. These four genera form a distinct group within tribe Tambiniini. They can be distinguished from the other known genera in the tribe by the head relatively dorsoventrally depressed, produced in front of eyes, but not extreme produced into a linguiform prolongation, apex not broadly rounded to base of frons, and hind tibia with two lateral spines. The four genera can be distinguished as follows:

1 Two carinae on each side of pronotum between eye and tegula and an incomplete carina behind eye.

Nesotaxila

- $\quad$ At most only one complete and one incomplete carina on each side of pronotum between eye and tegula.....

2 One complete and one incomplete carina on either side of pronotum between eye and tegula; vertex with sublateral carinae distinct and stubby

Kallitaxila

- $\quad$ A single carina laterally on pronotum between eye and tegula; vertex without sublateral carinae, if not, only slender sublateral carinae present. .3

3 Forewings with corium granulate; anal tube extreme long, distinctly surpassing terminal of genitalia, aedeagus a simple tube with accompanying spike...

Kallitambinia

- $\quad$ Forewings with corium not granulate, or only obscurely granulation present; anal tube relatively short, not surpassing or slightly surpassing surpassing terminal of genitalia

Tambinia

\section{Check list of species of Tambinia Stål}

atrosignata Distant, 1906; Sri Lanka (Paradeniya).

bizonata Matsumura, 1914; China (Taiwan), Japan.

capitata Distant, 1906; Burma, Malay States, India.

conus sp. n.; Papua New Guinea.

debilis Stål, 1859; India, Sri Lanka, Vietnam, South China (Anhui Province, Guangdong Province, Guangxi Zhuang Autonomous Region, Zhejiang Province, 
Fujian Province, Hainan Island, Hong Kong, Taiwan), Japan, Malacca, Malaysia, Singapore.

exoleta Melichar, 1914; New Guinea (Moroka).

fasciculosa Melichar, 1914; New Guinea (Moroka).

guamensis Metcalf, 1946; Micronesia (Guam).

inconspicua Distant, 1906; Burma.

languida Stål, 1859; Sri Lanka.

macula sp. n.; Malaysia (Borneo).

menglunensis Men \& Qin, 2009; China (Yunnan Province).

pitho Fennah, 1970; Philippines.

robustocarina sp. n.; Malaysia (Sabah).

rubrolineata Liang, 2003; South China (Hainan Island), Laos, Vietnam.

rubromaculata Distant, 1916; Sri Lanka.

rufoornata Stål, 1859; Sri Lanka.

sexmaculata sp. n.; Australia (Kuranda).

similis Liang, 2003; Vietnam.

sisyphus Fennah, 1956; Micronesia (Western Caroline Islands: Palau).

theivora Fennah, 1982; Malaysia (Cameron Highlands).

venusta (Kirkaldy, 1906); Australia (Queensland), New Guinea.

verticalis Distant, 1916; India (Southern India, Coorg, Madras), Zanzibar, Tanga. zonata Muir, 1931; India (Madras).

\section{Key to species of genus Tambinia}

1 Vertex shorter in middle than the widest breadth, or about as long as broad...2

- $\quad$ Vertex distinctly longer in middle than the widest breadth........................11

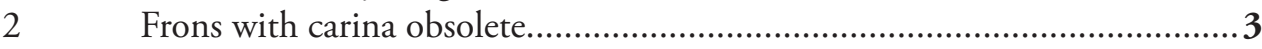

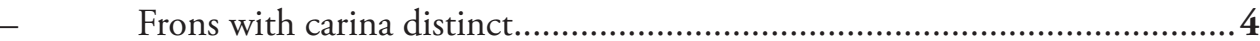

3 Frons about as long as broad, forewings with two black elongate spots near bases of sutural margins, nodal line marked with several fuscous spots (see Distant, 1906: 278) T. atrosignata Distant

- $\quad$ Frons (Fig. 3C) distinctly longer than broad, forewings (Figs 1B, 3D) with two red elongate marks near bases of sutural margins, many orange or red spots marked from basal part to nodal line, nodal line suffused with one transverse orange to red band. T. macula sp. $\mathrm{n}$.

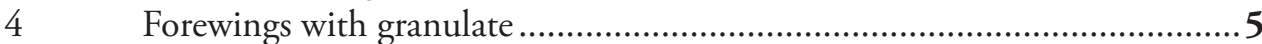

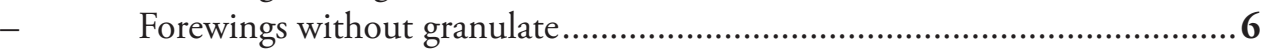

$5 \quad$ Forewings marked without transverse bands (see Distant 1906: 279, Fig. 129; Distant 1906: 277) T. debilis Stål

- $\quad$ Forewings marked with two brown transverse bands across wing sub-basally, on nodal line and in clavus (Yang et al. 1989: 80, Fig.6) 
Forewings with nodal line near apex .......................................................

Forewings with nodal line near middle .................................................... 9

Forewings with marks and stripes very pale, nearly absent (Fig. 1C)

T. similis Liang

Forewings with 11 apical cells, 4-5 subapical cells (see Liang 2003: 511; Fig. 1) T. rubrolineata Liang

Forewings with 9 apical cells, 3-4 subapical cells (see Fennah 1982: 641, Fig. 35)

T. theivora Fennah

Body suffused with distinct spots and markings

10

Body (Fig. 1D) without spots and markings, median carinae of vertex and pronotum thickened and broad, frons (Fig. 4C) with basal part of median carina strongly broad and thickened, not reaching to frontoclypeal suture, obsolete on level of antennae ................................... T. robustocarina sp. n.

10 Vertex, pronotum and mesonotum marked with reddish spots, forewings with nodal line suffused with red stripes (see Men and Qin 2009: 263, Figs 1, 2) T. menglunensis Men \& Qin

Vertex without spots, pronotum with posterior margin marked with reddish stripes, mesonotum with carinae reddish, forewings with nodal line suffused with fuscous (see Distant 1906: 278)

T. rufoornata Stål

11 Vertex medially $1.1-1.3$ times as long as maximum breadth 12

Vertex medially 1.4-1.8 times as long as maximum breadth 18 Body above suffused with marks or different colors 13 Body above concolorous, without marks or different colors 16 Vertex with sublateral carinae basally between median carina and lateral margins Vertex without sublateral carinae between median carina and lateral margins.. 15 Vertex (Figs 1E, 5A) with six red spots, pronotum and mesonotum without spots, forewings (Figs 1E, 5D) with two pairs of red spots near bases of sutural margins and distad of level of union of claval veins relatively.

T. sexmaculata sp. $\mathbf{n}$.

Vertex (Figs 1A, 2A) with two short reddish stripes, pronotum with a pair of orange spots outside lateral carinae, carinae on vertex and pronotum orange, mesonotum with a pair of orange spots beside lateral carinae near posterior margin, forewings (Figs 1A, 2D) with many reddish spots marked from basal part to nodal line

T. conus sp. $\mathrm{n}$.

15 Carinae on vertex, pronotum and mesonotum without pigmentation, mesonotum suffused with ochraceous (see Distant 1906: 276, Fig. 127)

T. languida Stål

- $\quad$ Carinae on vertex, pronotum and mesonotum reddish, mesonotum suffused with dark brown (see Muir 1931: 303)

T. zonata Muir 
- $\quad$ Head gradually narrowed to apex (see Distant 1906: 278)

T. capitata Distant

17 Forewings with $\mathrm{Cu}_{1}$ forking distad of level of union of claval veins, with 12 apical cells, subapical cells less than 5 (see Fennah 1956: 188, Fig. 54 a, d, g)

T. guamensis Metcalf

- $\quad$ Forewings with $\mathrm{Cu}_{1}$ forking basad of level of union of claval veins, with 14 apical cells, subapical cells more than 6 (see Fennah 1970: 77, Fig. 46)

T. pitho Fennah

18 Body concolorous, without marks or different colors

Body suffused with marks or different colors....

19 Vertex medially 1.4 times as long as maximum breadth, pronotum without short carinae between median carina and lateral margin (see Distant 1906: 277, Fig. 128)

T. inconspicua Distant

- Vertex medially 1.7 times as long as maximum breadth, pronotum with a pair of short carinae basally between median carina and lateral margins (see Fennah 1956: 189, Fig. 54 e, f, i) T. sisyphus Fennah

20 Forewings with nodal line suffused with pigmentation. 21 Forewings with nodal line concolorous, without pigmentation 22

21 Vertex and pronotum with orange marks, nodal line suffused with fuscous (see Wilson 1986: 386, Figs 1, 3)

T. verticalis Distant

- Vertex, pronotum and mesonotum red, carinae green (see Wilson and Malenovský 2007, Fig. 3)

T. fasciculosa Melichar

22 Forewings suffused with marks. 23 Forewings without marks (see Melichar 1914: 86) T. exoleta Melichar

23 Vertex and pronotum finely marked with red spots (see Distant 1916: 48) ... T. rubromaculata Distant

- Vertex marked with six red spots, pronotum with lateral carinae red (see Melichar 1914: 87)

T. venusta Kirkaldy

\section{Tambinia conus sp. $\mathbf{n}$.}

urn:lsid:zoobank.org:act:B4955F97-4D85-485C-8200-345005DD0F1B http://species-id.net/wiki/Tambinia_conus

Figs 1A, 2A-H

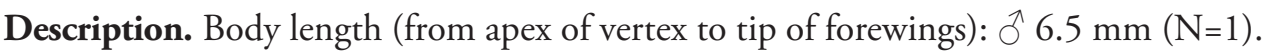

Colour. General colour tawny yellow, vertex (Figs 1A, 2A) with two short reddish stripes, pronotum (Figs 1A, 2A) with a pair of orange spots outside lateral carinae, median carinae on vertex and pronotum orange, mesonotum (Figs 1A, 2A) with a pair of orange spots beside lateral carinae near posterior margin, genae (Fig. 2B) with orange patch between eye and lateral margin of frons, forewings (Figs 1A, 2D) with many reddish spots marked from basal part to nodal line, tips of spines on hind tibiae and tarsi black. 


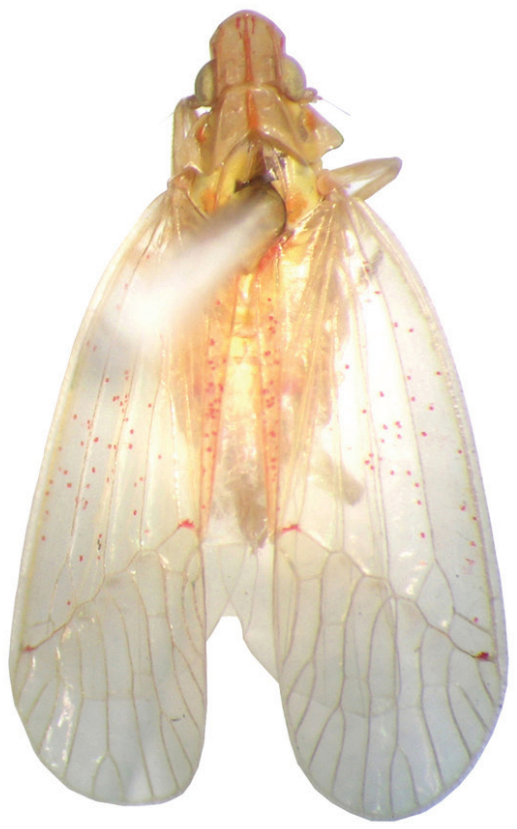

A

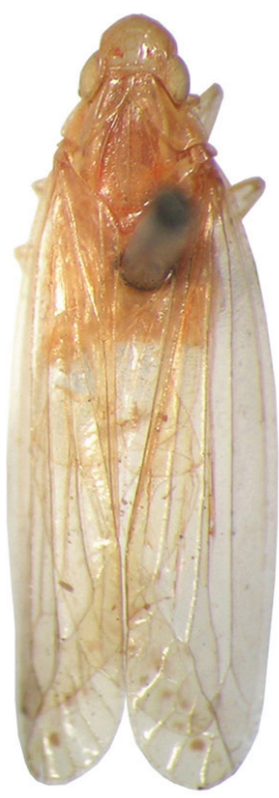

$\mathrm{C}$

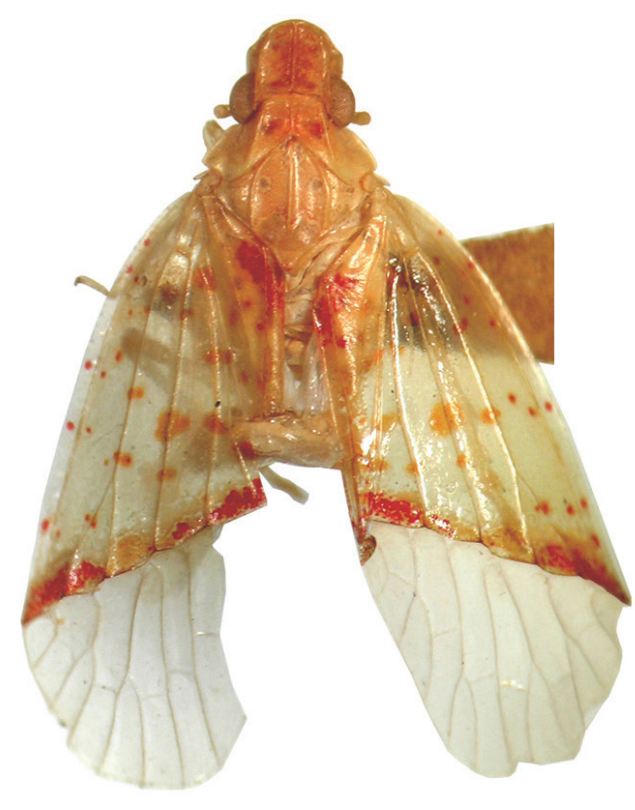

B

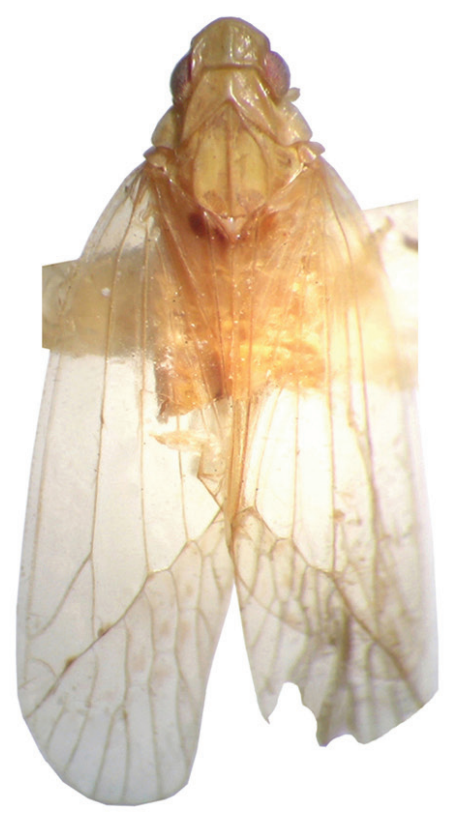

$\mathrm{D}$

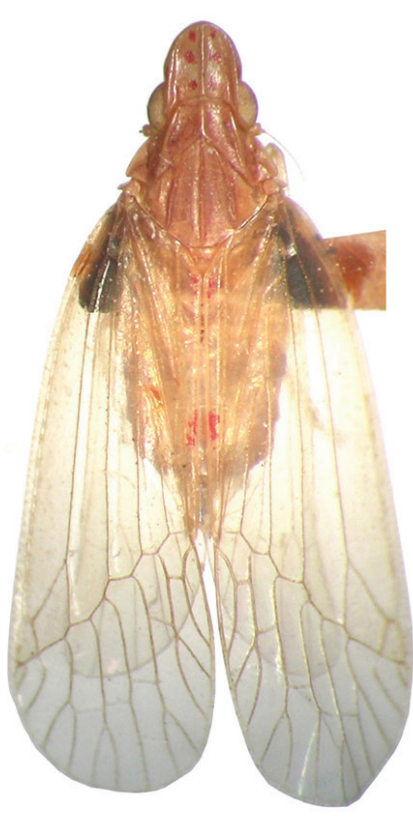

$\mathrm{E}$

Figure I. Dorsal habitus of Tambinia species A T. conus sp. n. (male, Papua New Guinea, CAS) B T. macula sp. n. (male, Malaysia:Borneo, CAS) C T. similis Liang (male, Vietnam, BPBM) D T. robustocarina sp. n.( male, Malaysia: Sabah, USUM) E T. sexmaculata sp. n.( male, Australia:Kuranda, CAS). 

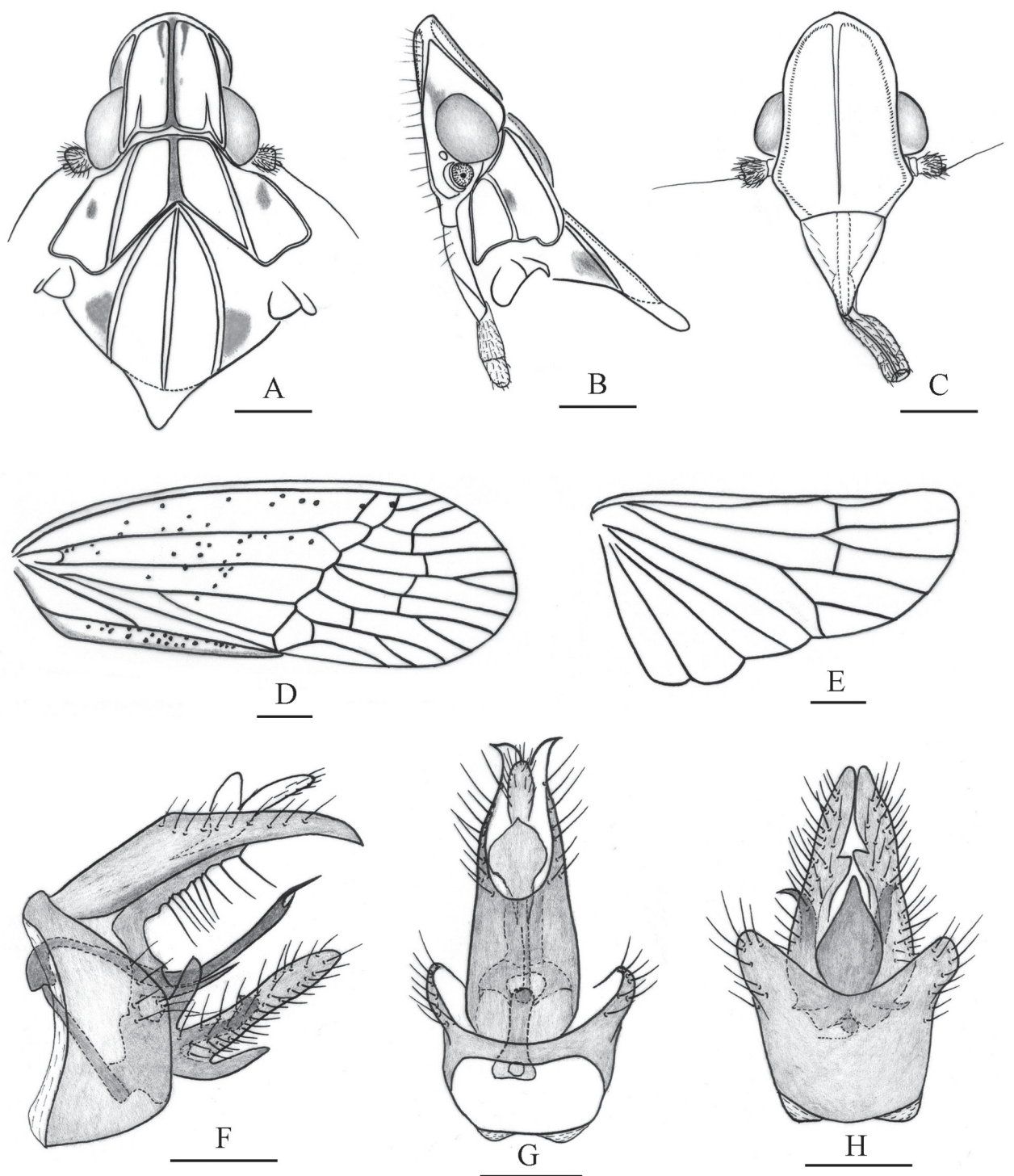

Figure 2. Tambinia conus sp. n. A head, pronotum and mesonotum, dorsal view B head, pronotum and mesonotum, lateral view $\mathbf{C}$ head, ventral view $\mathbf{D}$ right fore wing $\mathbf{E}$ right hind wing $\mathbf{F}$ male genitalia, left view $\mathbf{G}$ anal segment and pygofer, dorsal view $\mathbf{H}$ pygofer and gonostylus, ventral view. Scale bars: Figs $\mathrm{A}-\mathrm{C}=0.25 \mathrm{~mm} ; \mathrm{D}-\mathrm{E}=0.5 \mathrm{~mm} ; \mathrm{F}-\mathrm{H}=0.25 \mathrm{~mm}$.

Head and thorax. Head (Figs 1A, 2A, 2B) projecting before eyes approximately median length of eye, strongly dorsoventrally depressed. Vertex (Figs 1A, 2A) slightly longer in middle than the widest breadth $(1.1: 1)$, distinctly longer than pronotum at midline (1.6: 1); anterior margin projected at an obtuse angle in dorsal view, lateral margins ridged and converged anteriorly; median carina thin and percurrent, with 
a pair of short sublateral carinae basally between median carina and lateral margins; posterior margin straight. Frons (Fig. 2C) longer in middle than the widest breadth (1.4: 1), disc flat and smooth, covered with sparsely microsetae (Fig. 2B); lateral margins sinuous, diverging from apex, slightly concave at level of eyes, then diverging further to reach their widest point before converging to the clypeus; median carina slender, gradually thinning and obsolete posteriorly, almost reaching to frontoclypeal suture. Clypeus (Fig. 2C) triangular, with broad median carina. Pronotum (Figs 1A, 2A) distinctly shorter than mesonotum in midline (0.4: 1), carinae strongly ridged, lateral carinae diverging posteriorly, median carina distinct, reaching posterior margin. Pronotum and mesonotum together medially 2.2 times as long as median length of vertex. Hind tibiae each with 2 distinct lateral spines; spinal formula of hind leg 5-5-2. Forewings (Figs 1A, 2D) relatively elongate and narrow, 2.7 times as long as maximum breadth, with corium smooth, not granulate, Sc+R forking at $2 / 5$ apical, $\mathrm{Cu}_{1}$ forking after level of junction of claval veins, cell Sc with a short cross vein at its apical angle, with 13 apical cells and 6 subapical cells, claval veins uniting basad of middle of clavus.

Male genitalia. Pygofer (Figs 2F-H) narrow and relatively high, wider ventrally than dorsally, anterior margin moderately concave, posterior margin nearly straight on ventral half in lateral view. Anal tube (Figs 2F, 2G) distinctly elongate, surpassing to apex of gonostylus, ventral margin slightly bent ventrad in lateral view; lateral margins narrowing distad, apical margin distinctly forked in dorsal view; anal styles relatively short and stout, not surpassing apex of anal tube in dorsal view. Gonostylus (Figs 2F, $2 \mathrm{H})$ very narrow, apical part dorsoposteriorly directed in lateral view; median conical process distinctly elongate and strong, sclerotized, nearly reaching to middle part of gonostylus in ventral view. Periandrium (Fig. 2F) distinctly short, ring-shape, with a long process directed caudad at ventral side, surround aedeagusat medially. Aedeagus (Fig. 2F) with shaft sinuate and apical half dorsoposteriorly directed in lateral view, apical part forking at endosoma, forming two process, which dorsal one distinctly longer than the ventral one; endosoma membranous, slightly expanded.

Material examined. Holotype $\delta$, PAPUA NEW GUINEA: Madang Province, Finisterre Range, Teptep, stream NE of town, 2100-2560 m, 23 Mar 1989, Stop \#8940A, D. H. Kavanaugh and G. E. Ball collectors, PAPUA NEW GUINEA EXPEDITION-1989 (CAS).

Etymology. This new species is named for the presence of a strong median conical process at apically inner margin of gonostylus (Figs $2 \mathrm{~F}, 2 \mathrm{H}$ ).

Distribution. Papua New Guinea.

Remarks. This species is similar to T. languida Stål, 1859 collected from Sri Lanka, but can be distinguished from the latter in the vertex with two short reddish stripes, pronotum with a pair of orange spots outside lateral carinae, carinae of vertex and pronotum orange, mesonotum with a pair of orange spots beside lateral carinae near posterior margin, forewings with many reddish spots marked from basal part to nodal line and the frons with ratio of median length to the widest breadth 1.4:1 (in T. languida, vertex and pronotum without pigmentation, mesonotum sometimes suffused 
with ochraceous, the frons with ratio of median length to the widest breadth $2: 1$, see Stål, 1859: 317; Melichar, 1914: 85).

\section{Tambinia macula sp. $\mathrm{n}$.}

urn:lsid:zoobank.org:act:AD6252E1-EF47-441F-A4CC-8F6D1A721CE8

http://species-id.net/wiki/Tambinia_macula

Figs $1 \mathrm{~B}, 3 \mathrm{~A}-\mathrm{H}$

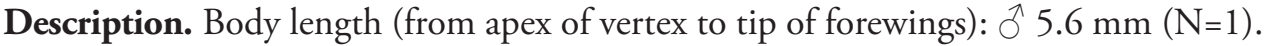

Colour. General colour ocherous, vertex (Figs 1B, 3A) with median carina suffused reddish, the reddish extending from the sides, forming two reddish long stripes, its outer margins irregular, pronotum (Figs 1B, 3A) with a pair of reddish spots at disc depression between median and lateral carinae, frons (Fig. 3C) suffused with pale reddish, forewings (Figs 1B, 3D) with basal portion ocherous, with two red elongate marks near bases of sutural margins, many orange or red spots marked from basal part to nodal line, nodal line suffused with one transverse orange to red band, tips of spines on hind tibiae and tarsi black.

Head and thorax. Head (Figs 1B, 3A) projecting before eyes approximately median length of eye, strongly dorsoventrally depressed. Vertex (Figs 1B, 3A) about as long as broad, two times as long as median length of pronotum, anterior margin projected at an obtuse angle in dorsal view, lateral margins ridged and converged anteriorly; median carina thin and percurrent; posterior margin straight. Frons (Fig. 3C) longer in middle than the widest breadth (1.3: 1), disc slightly depressed, covered with sparsely microsetae (Figs 3B, 3C); lateral margins sinuous, diverging from apex, slightly concave at level of eyes, then diverging further to reach their widest point before converging to the clypeus; without median carina. Clypeus (Fig. 3C) triangular, without median carina. Pronotum (Figs 1B, 3A) distinctly shorter than mesonotum in midline (0.3: 1), carinae strongly ridged, lateral carinae diverging posteriorly, median carina distinct, reaching posterior margin. Pronotum and mesonotum together medially 2.1 times as long as median length of vertex. Hind tibiae each with 2 distinct lateral spines; spinal formula of hind leg 5-5-2. Forewings (Figs 1B, 3D) relatively broad, with basal portion semihyaline, thicker than apical portion, without granulation, 2.7 times as long as maximum breadth, $\mathrm{Sc}+\mathrm{R}$ forking about medially, $\mathrm{Cu}_{1}$ forking after level of junction of claval veins, cell Sc with a short cross vein at its apical angle, with 12 apical cells and 5 subapical cells, claval veins uniting distad of middle of clavus.

Male genitalia. Pygofer (Figs 3E, 3G, 3H) narrow and high, wider ventrally than dorsally, anterior margin concave medially, posterior margin produced caudad in lateral view. Anal tube (Figs 3E, 3F) relatively elongate, ventral margin nearly straight and directed caudad in lateral view; lateral margins slightly diverging distad, apical margin concave in dorsal view; anal styles relatively long, distinctly surpassing apex of anal tube in dorsal view. Gonostylus (Figs 3E, 3G, 3H) elongate, basal half broad and apical half abruptly narrow in lateroventral view; median conical process very thin and slen- 

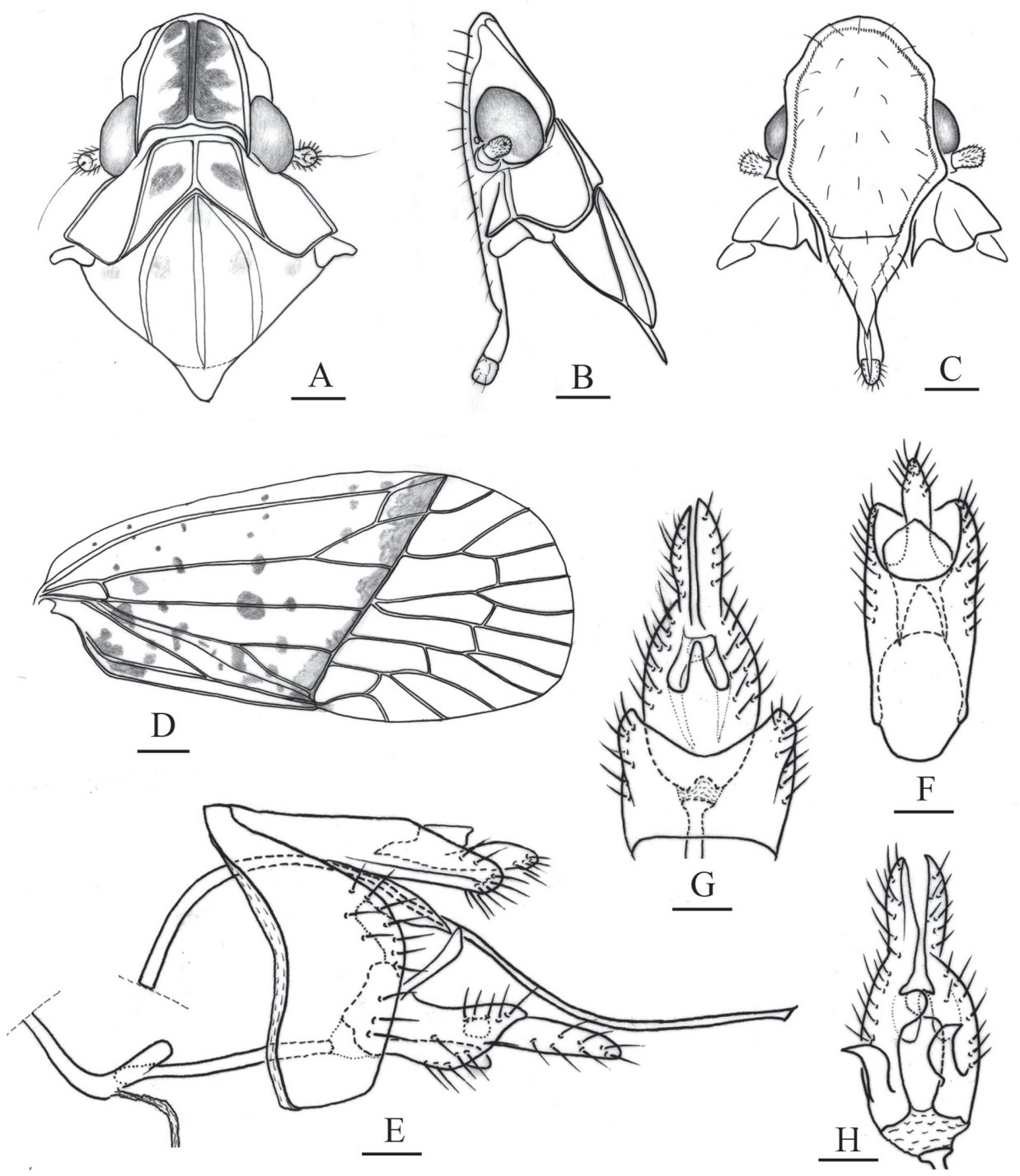

Figure 3. Tambinia macula sp. n. A head, pronotum and mesonotum, dorsal view $\mathbf{B}$ head, pronotum and mesonotum, lateral view $\mathbf{C}$ head, ventral view $\mathbf{D}$ right fore wing $\mathbf{E}$ male genitalia, left view $\mathbf{F}$ anal segment, dorsal view $\mathbf{G}$ pygofer and gonostylus, ventral view $\mathbf{H}$ gonostylus, dorsal view. Scale bars: Figs $\mathrm{A}-\mathrm{D}=0.25 \mathrm{~mm} ; \mathrm{E}-\mathrm{H}=0.125 \mathrm{~mm}$.

der, sclerotized in ventral view. Periandrium (Fig. 3E) tube-like, distinctly sclerotized, with a short process directed ventrad at dorsal apex, surrounding aedeagus medially. Aedeagus (Fig. 3E) with shaft very long and thin, simple tubule, sinuate and its apex directed caudad in lateral view, endosoma indistinct.

Material examined. Holotype $\widehat{\jmath}$, MALAYSIA: Banaakan Borneo, 1927.I, Pemberton Coll. (CAS). 
Etymology. This new species is named for the presence of many reddish markings on vertex, pronotum and tegmina (Fig. 1B).

Distribution. Malaysia (Borneo).

Remarks. This species is similar to T. atrosignata Distant, 1906, but can be distinguished from the latter in vertex with two reddish long stripes, pronotum with a pair of reddish spots, forewings with basal portion ocherous, with two red elongate marks near bases of sutural margins, many orange or red spots marked from basal part to nodal line and nodal line suffused with one transverse orange to red band.

\section{Tambinia robustocarina sp. $\mathbf{n}$.}

urn:lsid:zoobank.org:act:4583165F-DBE6-4F7A-AA36-FC1FBF6369FF http://species-id.net/wiki/Tambinia_robustocarina

Figs $1 \mathrm{D}, 4 \mathrm{~A}-\mathrm{G}$

Description. Body length (from apex of vertex to tip of forewings): $016.8 \mathrm{~mm}(\mathrm{~N}=1)$.

Colour. General colour tawny yellow, forewings (Figs 1D, 4D) with two fuscous elongate marks near bases of sutural margins, nodal line suffused with pale brown marks, many fuscous spots marked from nodal line to apex, tips of spines on hind tibiae and tarsi black.

Head and thorax. Head (Figs 1D, 4A) projecting before eyes approximately $3 / 5$ median length of eye, not strongly dorsoventrally depressed. Vertex (Figs 1D, 4A, 4B) distinctly shorter in middle than the widest breadth (0.6: 1$)$, distinctly longer than pronotum at midline (1.7: 1), anterior margin convex, broadly callused, uniting with base of frons to form smooth surface, lateral margins ridged and converged anteriorly, median carina long and percurrent, thickened and broad, posterior margin straight. Frons (Fig. 4C) slightly longer medially than greatest width (1.3: 1), disc flat and smooth, covered with sparsely microsetae (Fig. 4B), lateral margins diverging to below level of eyes, distinctly callused; median carina with basal part strongly broad and thickened, not reaching to frontoclypeal suture, obsolete on level of antennae. Clypeus (Fig. 4C) triangular, with distinctly broad median carina. Pronotum (Figs 1D, 4A) distinctly shorter than mesonotum in midline (0.2: 1), carinae broadly ridged, lateral carinae diverging posteriorly, median carina distinctly thickened and broad, reaching posterior margin. Pronotum and mesonotum together medially 3.0 times as long as median length of vertex. Hind tibiae each with 2 distinct lateral spines; spinal formula of hind leg 5-5-2. Forewings (Figs 1D, 4D) relatively elongate and narrow, 3.0 times as long as maximum breadth, with corium smooth, not granulate, $\mathrm{Sc}+\mathrm{R}$ forking at apical 2/5, $\mathrm{Cu}_{1}$ forking after level of junction of claval veins, with 11 apical cells and 6 subapical cells, claval veins uniting at about middle of clavus.

Male genitalia. Pygofer (Figs 4E-G) irregular subquadrate in lateral view, anterior margin concave on dorsal $1 / 3$, posterior margin produced caudad in lateral view. Anal tube (Figs 4E, 4F) relatively elongate, ventral margin slightly bent ventrad in lateral view; lateral margins convex medially then narrowing distad, apical margin slightly 

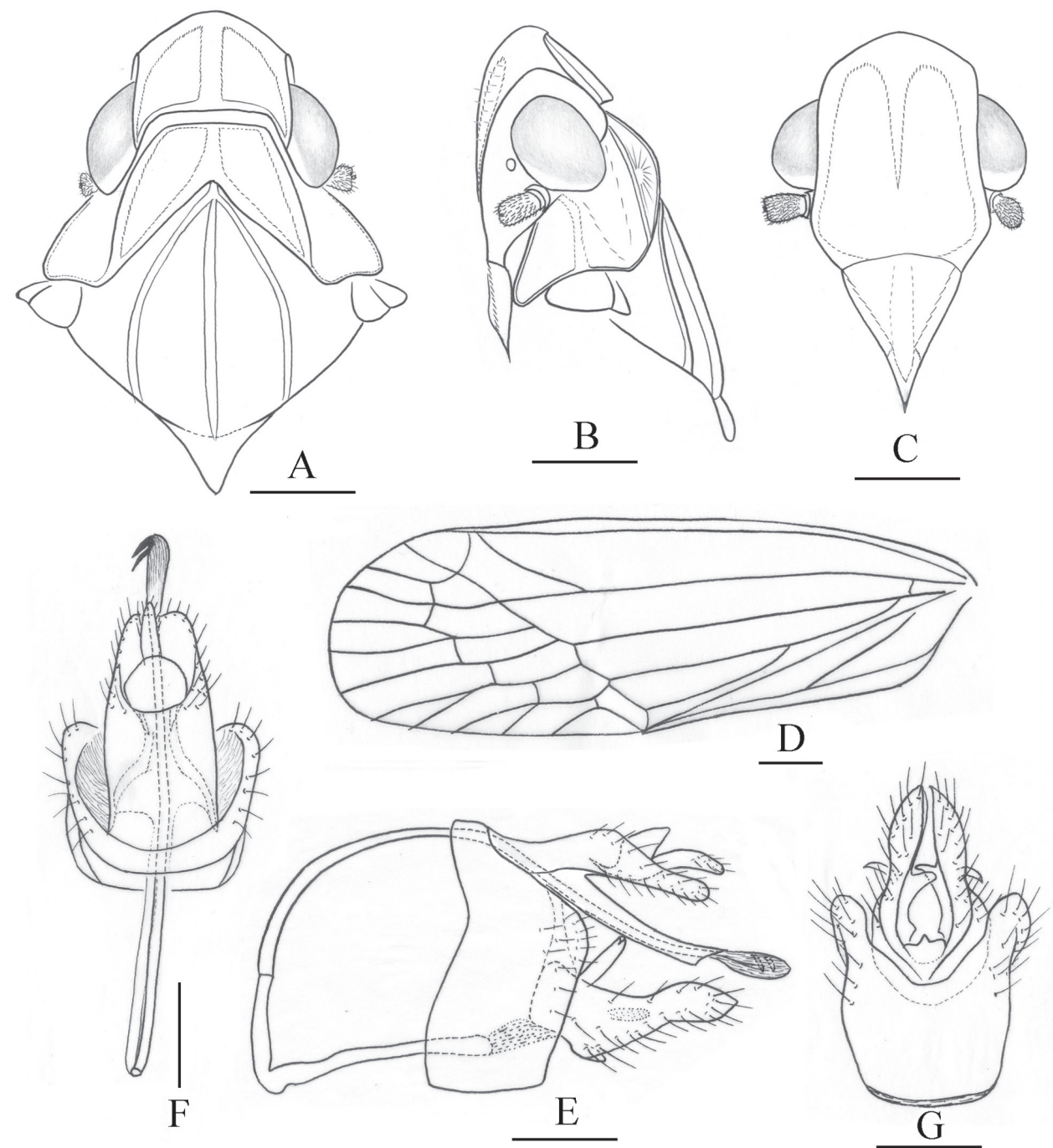

Figure 4. Tambinia robustocarina sp. $n$. A head, pronotum and mesonotum, dorsal view B head, pronotum and mesonotum, lateral view $\mathbf{C}$ head, ventral view $\mathbf{D}$ left fore wing $\mathbf{E}$ male genitalia, left view $\mathbf{F}$ male genitalia, dorsal view $\mathbf{G}$ pygofer and gonostylus, ventral view. Scale bars: Figs A-C $=0.25 \mathrm{~mm}$; D $=0.5$ $\mathrm{mm} ; \mathrm{E}-\mathrm{G}=0.25 \mathrm{~mm}$.

concave in dorsal view; anal styles relatively long and narrow, surpassing apex of anal tube in dorsal view. Gonostylus (Figs $4 \mathrm{E}, 4 \mathrm{G}$ ) elongate, but not surpassing to apex of gonostylus, apical half narrow and basal half broad in lateral view; median conical process very small, sclerotized in ventral view. Periandrium (Fig. 4E) distinctly elongate and slender, tube-like, distinctly sclerotized, with a short process directed caudad at dorsal apex, surrounding aedeagus subapically. Aedeagus (Figs 4E, 4F) with shaft thin and tubular, arched and its apex directed ventrad in lateral view, endosoma membra- 
nous, moderately expanded, with two, anteroventrally directed, spinous processes on right side in lateral view.

Material examined. Holotype ${ }^{\lambda}$, MALAYSIA: Malaysia: Sabah: $25 \mathrm{~km}$ N Tambunan, 1500 m, 1983.IX.3, at black light, G. F. Hevel \& W. E. Steiner (USNM).

Etymology. This new species is named for the presence of a robust median carina on the vertex (Figs 1D, 4A).

Distribution. Malaysia (Sabah).

Remarks. Based on the following combination of characters: head relatively short, not strongly dorsoventrally depressed, broadly produced anteriorly; vertex with median carina strongly thickened and broad; pronotum with median carina relatively broad and frons with basal part of median carina strongly broad and thickened, this species and the four previously described species, T. menglunensis, T. rubrolineata, $T$. similis and T. theivora form a very distinct group within Tambinia.

In external appearance, this species is similar to T. similis (Fig. 1C) and but differs from the latter in the median carina on vertex long and percurrent, thickened and broad, but not spatula-like, forewings relatively broad, nodal line relatively near middle and cell Sc without a short cross vein at its apical angle. This species is also similar to T. menglunensis (see Men and Qin, 2009: 263, Figs 1, 2), but differs from the latter in the obsolete spots and markings on the vertex, pronotum, mesomotum and forewings, median carinae on vertex, pronotum and frons strongly thickened and broad, and gonostylus with median conical process very small.

\section{Tambinia sexmaculata sp. n.}

urn:Isid:zoobank.org:act:56274E10-6B5F-41CC-9DB7-563446EC4CD2

http://species-id.net/wiki/Tambinia_sexmaculata

Figs 1E, 5A-H

Description. Body length (from apex of vertex to tip of forewings): $\widehat{\delta} 6.2 \mathrm{~mm}(\mathrm{~N}=1)$, १, 6.6-6.8 $\mathrm{mm}(\mathrm{N}=2)$.

Colour. General colour tawny yellow, vertex (Figs 1E, 5A) with six red spots, genae (Fig. 5B) with orange patch between eye and lateral margin of frons, forewings (Figs $1 \mathrm{E}, 5 \mathrm{D})$ with two pairs of red spots near bases of sutural margins and distad of level of union of claval veins, relatively, tips of spines on hind tibiae and tarsi black.

Head and thorax. Head (Figs 1E, 5A) projecting before eyes 1.2 times as long as median length of eye, strongly dorsoventrally depressed. Vertex (Figs 1E, 5A) distinctly longer in middle than the widest breadth (1.1: 1), distinctly longer than pronotum at midline (2.3: 1); anterior margin projected at an obtuse angle in dorsal view, lateral margins ridged and converged anteriorly; median carina thin and percurrent, with a pair of short sublateral carinae basally between median carina and lateral margins; posterior margin nearly straight. Frons (Fig. 5C) longer in middle than the widest breadth (1.6: 1), disc flat and smooth, covered with very sparsely microsetae (Figs 5B, 5C); lateral margins sinuous, diverging from apex, slightly concave at level of eyes, then slightly diverging to 

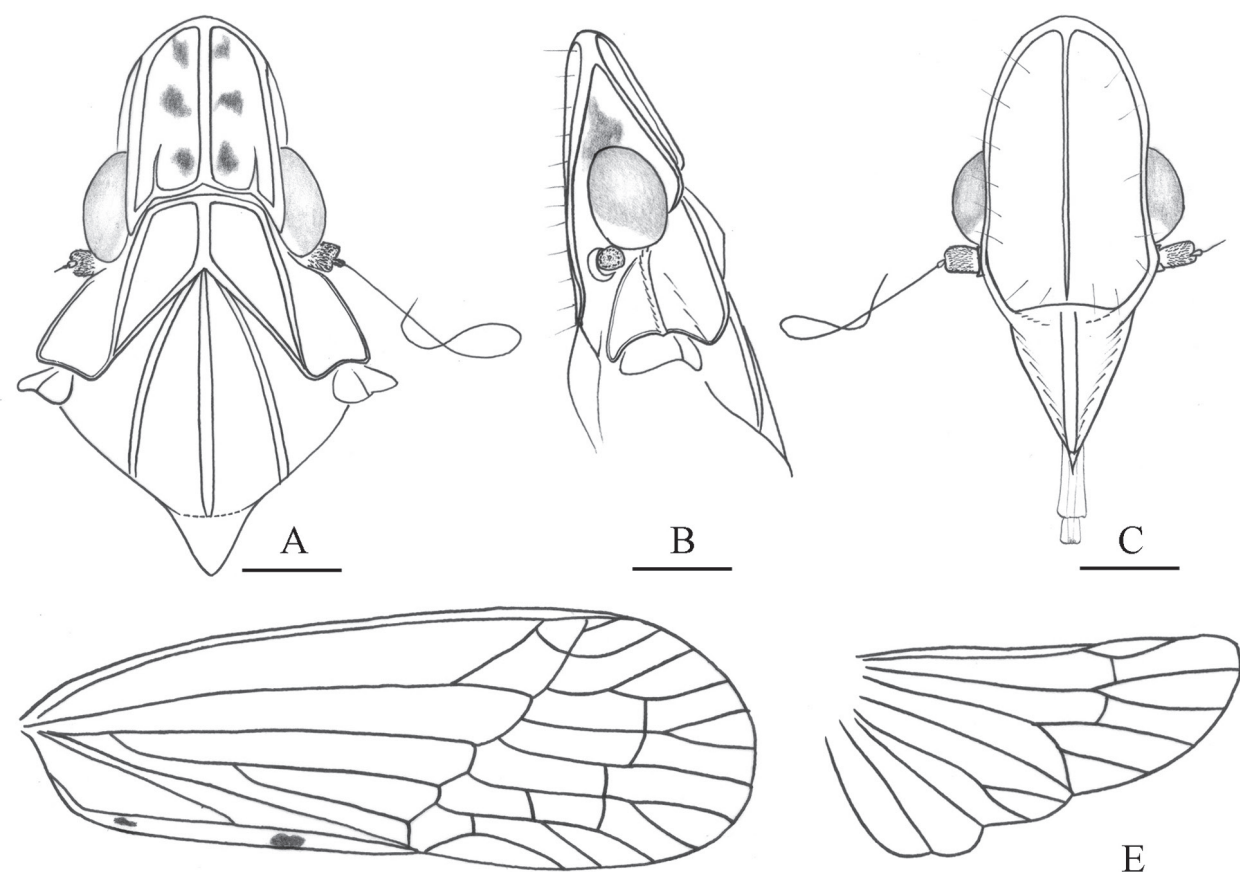

$\mathrm{D}$
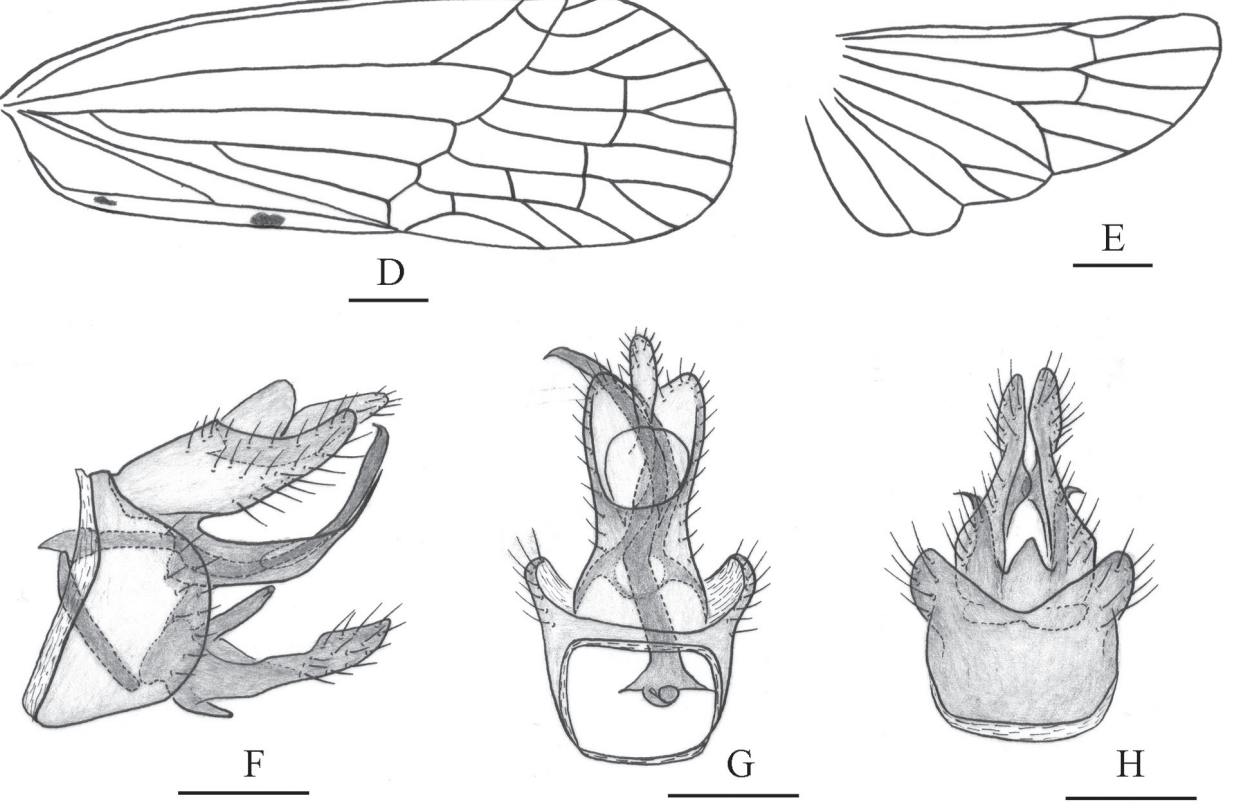

Figure 5. Tambinia sexmaculata sp. n. A head, pronotum and mesonotum, dorsal view B head, pronotum and mesonotum, lateral view $\mathbf{C}$ head, ventral view $\mathbf{D}$ right fore wing $\mathbf{E}$ right hind wing $\mathbf{F}$ male genitalia, left view $\mathbf{G}$ male genitalia, dorsal view $\mathbf{H}$ pygofer and gonostylus, ventral view. Scale bars: Figs $\mathrm{A}-\mathrm{C}=0.25 \mathrm{~mm} ; \mathrm{D}-\mathrm{E}=0.5 \mathrm{~mm} ; \mathrm{F}-\mathrm{H}=0.25 \mathrm{~mm}$.

reach their widest point before converging to the clypeus; median carina long and slender, nearly reaching to frontoclypeal suture. Clypeus (Fig. 5C) triangular, with distinct median carina. Pronotum (Figs 1E, 5A) distinctly shorter than mesonotum in midline (0.3: 1), carinae strongly ridged, lateral carinae moderately diverging posteriorly, median 
carina distinct, reaching posterior margin. Pronotum and mesonotum together medially 2.0 times as long as median length of vertex. Hind titiae each with 2 distinct lateral spines; spinal formula of hind leg 4-5-2. Forewings (Figs 1E, 5D) relatively elongate and narrow, 2.8 times as long as maximum breadth, with corium smooth, not granulate, $\mathrm{Sc}+\mathrm{R}$ forking at 2/5 apical, $\mathrm{Cu}_{1}$ forking at level of junction of claval veins, with 12-13 apical cells and 5 subapical cells, claval veins uniting distad of middle of clavus.

Male genitalia. Pygofer (Figs 5F-H) moderately broad, anterior margin concave on dorsal $1 / 3$, posterior margin convex caudad in lateral view. Anal tube (Figs 5F, 5G) distinctly elongate, almost surpassing to apex of gonostylus, ventral margin slightly curve dorsad in lateral view; lateral margins concave medially then diverging from apex, apical margin distinctly concaved in dorsal view; anal styles long and strong, surpassing apex of anal tube in dorsal view. Gonostylus (Figs 5F, 5H) very narrow, expanded subapically then narrowing to apex, directed caudad in lateral view; median conical process distinct, relatively short. Periandrium (Figs 5F, 5G) distinctly elongate and sclerotized, tube-like, surrounding aedeagus medially, with a long, sinuate process at left side, dorsoposteriorly directed. Aedeagus (Figs 5F, 5G) with shaft tubular, apical part abruptly curved through approximately $30^{\circ}$, directed to right; endosoma indistinct.

Material examined. Holotype $\tilde{\sigma}$, AUSTRALIA: Kuranda N. Q. Australia, 1904. VIII.10. Koebele, W. M. Giffard Collection (CAS). Paratypes. $2 q q$, the same data with Holotype (CAS).

Etymology. This new species is named for the presence of six reddish markings on vertex (Figs 1E, 5A).

Distribution. Australia (Kuranda).

Remarks. This species is similar to T. conus but can be distinguished from the latter in the vertex with six red spots, forewings with two pairs of red spots and by the male genitalia structure (Figs $5 \mathrm{~F}-\mathrm{H}$ ), especially the shape of anal tube, median conical process of gonostylus relatively small, periandrium relatively long, with a long, sinuate process at left side, dorsoposteriorly directed, and the shaft of aedeagus apical part abruptly curved through approximately $30^{\circ}$, directed to right.

\section{Acknowledgments}

The work on which this paper is based was supported by the following sources: the National Natural Science Foundation of China (grant number 30900145), awarded to RRW and the National Natural Science Foundation of China (grant numbers 30530110, 30770269, 30970400), a grant (No. O529YX5105) from the Key Laboratory of the Zoological Systematics and Evolution of the Chinese Academy of Sciences, the National Science Fund for Fostering Talents in Basic Research (Special subjects in animal taxonomy, NSFC-J0630964/J0109), all awarded to APL. 


\section{References}

Asche M, Wilson MR (1989) The plant-feeding planthopper genus Ommatissus (Homoptera, Fulgoroidea: Tropiduchidae). Systematic Entomology 14: 127-147. doi: 10.1111/j.13653113.1989.tb00271.x

Bourgoin T, Huang J (1990) Morphologie comparée des genitalia mâles des Trypetimorphini et remarques phylogénétiques (Hemiptera: Fulgoromorpha: Tropiduchidae). Annales de la Société Entomologique de France (Nouvelle Série) 26: 555-564.

Distant WL (1906) The Fauna of British India, Including Ceylon and Burma, Rhynchota 3 (Heteroptera-Homoptera), Taylor \& Francis, London, 175-491.

Distant WL (1916) The Fauna of British India, Including Ceylon and Burma, Rhynchota 6 (Heteroptera-Homoptera), Taylor \& Francis, London, 17-145.

Fennah RG (1956) Homoptera: Fulgoroidea. Insects of Micronesia 6(3): 1-211.

Fennah RG (1970) The Tropiduchidae collected by the Noona Dan Expedition in the Philippines and Bismarck Archipelago (Insect, Homoptera, Fulgoroidea). Steenstrupia 1: 61-82.

Fennah RG (1982) A tribal classification of the Tropiduchidae (Homoptera: Fulgoroidea), with the description of a new species on tea in Malaysia. Bulletin of Entomological Research 72: 631-643. doi: 10.1017/S0007485300008658

Ghauri MSK (1976) The genus Numicia from economic plants in the oriental region (Homoptera: Fulgoroidea). Systematic Entomology 1(1): 9-13. doi: 10.1111/j.1365-3113.1976. tb00027.x

Liang AP, Jiang GM (2003) Two new species of Tambinia Stål (Hemiptera: Tropiduchidae) from China, Laos and Vietnam, with description of eggs. Journal of the Kansas Entomological Society 76(3): 509-517.

Melichar L (1914) Monographie der Tropiduchinen (Homoptera). Verhandlungen des Naturforschenden Vereins in Brünn 53: 1-145.

Matsumura S (1914) Beitrag zur kenntnis der Fulgoriden Japans. Annales Historico-Naturales Musei Nationalis Hungarici 12: 261-305.

Men QL, Qin DZ, Liu GL (2009) A Taxonomic Study of the Genus Tambinia Stål (Hemiptera: Fulgoroidea: Tropiduchidae) from China. Entomotaxonomia 31(1): 6-8.

Metcalf ZP (1946) Insects of Guam. II. Homoptera. Fulgoroidea and Jassoidea of Guam. Bulletin of the Bernice P. Bishop Museum 189:105-148.

Metcalf ZP (1954) General Catalogue of the Homoptera. Fasc. IV. Fulgoroidea. Part 11. Tropiduchidae), North Carolina State College, Raleigh, NC, USA, 1-167.

Muir F (1931) New and little-known Fulgoroidea in the British Museum (Homoptera). Annals and Magazine of Natural History 7(10): 297-314.

O'Brien LB (2010) New species of New World Tambiniini from palms. Cicadina 11:3-12.

Stål C (1859) Novae quaedem Fulgorinorum formae speciesque insigniores. Berliner Entomologische Zeitschrift 3: 313-327.

Stål C (1870) Hemiptera insularum Philippinarum. Bidrag till Philippinska öarnes Hemipterafauna. Öfversigt af Kongl. Vetenskaps-akademiens förhandlingar 27: 607-776. 
Wang RR, Liang AP, Webb MD (2009) A new tropiduchid planthopper genus and species from China with descriptions of in copula genitalic structures (Hemiptera: Fulgoromorpha). Systematic Entomology 34: 434-442. doi: 10.1111/j.1365-3113.2009.00475.x

Wilson MR (1986) An Indian Tropiduchid planthopper Tambinia verticalis Distant (Hemiptera: Fulgoroi4a) breeding on coconut in Zanzibar. Bulletin of Entomological Research 76: 385-388. doi: 10.1017/S0007485300014875

Wilson MR, Malenovský I (2007) Tropiduchidae described by Leopold Melichar (Hemiptera, Fulgoromorpha). Acta Musei Moraviae, Scientiae biologicae (Brno) 92: 137-153.

Wilson SW, O’Brien LB (1987) A survey of planthoppers pests of economically important plants (Homoptera: Fulgoroidea). In: Wilson MR, Nault LR (Eds) Proceedings of 2nd International Workshop on Leafhoppers and Planthoppers of Economic Importance, Provo, Utah, USA, 28th July-1st August 1986. CAB International Institute of Entomology, London, 343-360.

Yang JT, Yang CT, Wilson MR (1989) Tropiduchidae of Taiwan (Homoptera: Fulgoroidea). Collected Papers on Homoptera of Taiwan, Taiwan Musesum Special Publication 8: 65115 . 